\title{
Sensoriamento remoto como suporte para estudos cartográficos sobre o território da América Portuguesa entre 1500 e 1822
}

\author{
Paulo R. Martini \\ Joaquim Godoi Filho \\ Ricardo G. C. Arduino \\ Sílvio P. Coimbra \\ Guilherme G. Silva ${ }^{1}$
}

RESUMO: Este artigo aborda a utilização de imagens de satélites como suporte para evidenciar a expansão histórico-cartográfica das fronteiras paulistas entre o descobrimento do Brasil e a sua independência, recurso esse utilizado na exposição Cartografia de uma história, realizada no Museu Paulista da USP em 2005. As imagens foram aquelas do Modis, do Shuttle Radar Topographic Mission e do Satélite Landsat-5. As cenas foram georreferenciadas valendo-se da ferramenta Spring e dos mosaicos georretificados disponibilizados pela Nasa. Sobre estes produtos foi lançado um valioso conjunto de informações cartográficas coletadas pelas pesquisadoras da Cátedra Jaime Cortesão da USP. O conjunto inclui o Tratado de Tordesilhas, com suas distorções, o Mapa das Cortes, as capitanias, as bandeiras, as monções, as trilhas, os tropeirismos, ou seja, todo o conjunto de ações pioneiras que permitiram consolidar o território paulista e grande parte da identidade espacial brasileira. Foram analisados também o mito da llha Brasil e os enlaces das bacias do rio Amazonas e do rio Paraná-Prata a partir dos atributos geomorfológicos dispostos nas imagens orbitais. Os resultados foram consolidados em um banco de dados de 800 megabites, sendo dispostos em exposição junto ao Museu Paulista. Este artigo descreve os procedimentos metodológicos de geração e de análise das imagens bem como sintetiza os resultados alcançados.

PALAVRAS-CHAVE: Sensoriamento Remoto. Cartografia Histórica. Museu Paulista. Expansão Paulista. América Portuguesa.

ABSTRACT: This article discusses the use of satellite imaging as a means to support and map out the historical expansion of the borders of São Paulo State between the discovery of Brazil and its independence. This tool was employed in Cartography of a history, an exhibition staged at Museu Paulista/USP in 2005. The images were generated by Modis, Shuttle Radar

\footnotetext{
1. Instituto Nacional de Pesquisas Espaciais-Inpe/MCT, Av. dos Astronautas, 1758 São José dos Campos, SP. CEP 12227-010. E-mails: $<$ martini@dsr.inpe.br > $<$ martini,joaquim,ricardo, coimbra,guilherme@dsr. inpe.br>.
} 
Topographic Mission and Landsat-5, and georeferenced with the SPRING image processor as well as georectified mosaics made available by Nasa. They were then checked against a valuable set of cartographic data collected by the researchers working under the Jaime Cortesão History Chair at USP. The said set included information pertaining to the boundaries established by the Treaty of Tordesillas, with its distortions; the Map of the Courts; the captaincies; as well as the trails of bandeiras (exploring expeditions), monções (expeditions made up and down the rivers of the São Paulo and Minas Gerais captaincies), and tropeirismos (cattle driving routes). In other words, all the pioneering actions that helped to consolidate the territory of São Paulo State and to shape much of Brazil's spatial identity were traced in the images. The researchers also looked into the myth of Brazil as an island and into the purported connection between the Amazon and Paraná-Prata river basins based on their geomorphologic attributes as shown on the orbital images. The results were compiled into an 800-megabyte database and displayed at Museu Paulista. This paper describes the methodological procedures used to generate and analyze the images, and provides a summary of the research findings. KEYWORDS: Remote sensing. Historical cartography. Museu Paulista. Expansion of São Paulo State. Portuguese America.

Antecedentes

A consolidação do território paulista, contada a partir do descobrimento, forma um rico painel de novas trilhas e novas fronteiras que colaboraram muito para o estabelecimento dos limites espaciais brasileiros. Ciente desse enfoque, a Cátedra Jaime Cortesão procurou o Inpe, no sentido de apresentar a história dos domínios territoriais paulistas segundo ferramentas e procedimentos menos convencionais e mais precisos, com base em sensoriamento remoto e geoprocessamento.

Os estudos partiram da documentação histórica e cartográfica recuperada pelas curadoras da exposição Cartografia de uma História, Iris Kantor e Beatriz Bueno, de sua leitura, análise e transposição para os produtos recolhidos dos bancos de imagens da Nasa e do Inpe, processados em ferramenta Spring. Os procedimentos para gerar os produtos, os métodos de análise aplicados a eles, bem como exemplos subamostrados das cartas produzidas estão apresentadas nos itens que se seguem.

\section{Os mosaicos Modis}

Modis (Espectro-radiômetro Imageador de Resolução Moderada) é um sensor de resolução média (500 metros), que opera em 36 faixas de espectro eletromagnético. Em duas das três plataformas que compõem a plêiade EOS-Earth Observation System, foram instalados dois sistemas idênticos. Essas duas plataformas são aquela da manhã (Terra) e aquela da tarde (Acqua). Com estas configurações, - Modis consegue coletar diariamente imagens de praticamente todo o planeta. As limitações provocadas pelas nuvens impõem que várias passagens sejam 
gravadas de forma a se compor os mosaicos livres de nuvens utilizados neste trabalho. A cobertura Modis da América do Sul é composta de 12 quadros individuais. Eles foram baixados um a um, em função da cobertura de nuvens, em bandas individuais correspondentes aos canais 1, 3 e 4, todos da faixa espectral correspondente ao visível. Os canais foram corrigidos radiometricamente de forma a se ter valores digitais mais coerentes entre os pixels e, também, produzir melhor contraste de tons entre eles.

Uma vez corrigidos na parte radiométrica, foram atribuídas cores (RGB) às respectivas bandas. À banda 1, da faixa vermelha, foi atribuída a cor vermelha; à banda 2 (faixa do azul), a cor azul; e à banda 3 (faixa do verde), a cor verde. curadoras da exposição $\bigcirc$ passo seguinte foi proceder à georreferenciação, onde são definidos o tipo de projeção cartográfica e a correção do posicionamento dos pixels na imagem, de forma que toda a cena se apresente com precisão aceitável para a escala do mapa. Tal processo é feito através de pontos de controle no terreno, conhecidos. Tais pontos dotam todos os demais com a categoria cartográfica necessária para se tomar medidas internas relativas (e. g. distâncias) e absolutas (latitudes, longitudes) dentro dos erros de precisão. No caso desses mosaicos Modis, o erro máximo é da ordem de quatro pixels ou 2 mil metros, valor que, para a escala de apresentação de 1:5.000.000, está dentro da precisão esperada.

A Figura 1 mostra o mosaico Modis utilizado neste trabalho, onde se reproduziu a América do Sul segundo cores naturais. Ao mosaico, são atribuídas cores RGB aos canais infra-vermelhos, sendo, portanto, cores falsas.

O Mosaico Modis serviu como suporte para transpor: o Tratado de Tordesilhas (Figura 2), o Mapa das Cortes (Figura 3), as bandeiras, monções e tropeirismo, bem como os diversos limites que as capitanias paulistas mostraram desde suas definições originais. Essas transposições foram feitas a partir da leitura de cópias de documentos e de mapas históricos, e da sua interpretação sobre as imagens. $\bigcirc$ desenho dos limites do Mapa das Cortes teve um suporte muito grande do Mapa de Cobertura Landsat/CBERS, em plano digital, na escala $1: 10.000 .000$.

\section{Mosaico SRTM}

A missão da Nasa designada SRTM-Shuttle RADAR Topographic Mission coletou um imenso volume de dados sobre os domínios terrestres do planeta valendo-se da tecnologia de sensores operando na faixa das micro-ondas. Nesta faixa, podem ser adquiridas imagens independentes da fonte natural de iluminação (sol) e de condições climáticas como cobertura de nuvens e chuva. Este atributo colocou o mosaico SRTM como ferramenta muito adequada para estudos do domínio sul americano, bastante comprometido com nuvens na Panamazônia e na região Periandina. A iluminação da cena, sendo gerada a bordo pelo próprio sensor, permite, também, que ângulos incidentes mais baixos realcem a topografia disposta nas imagens, atributo que contribui bastante para se analisarem as 


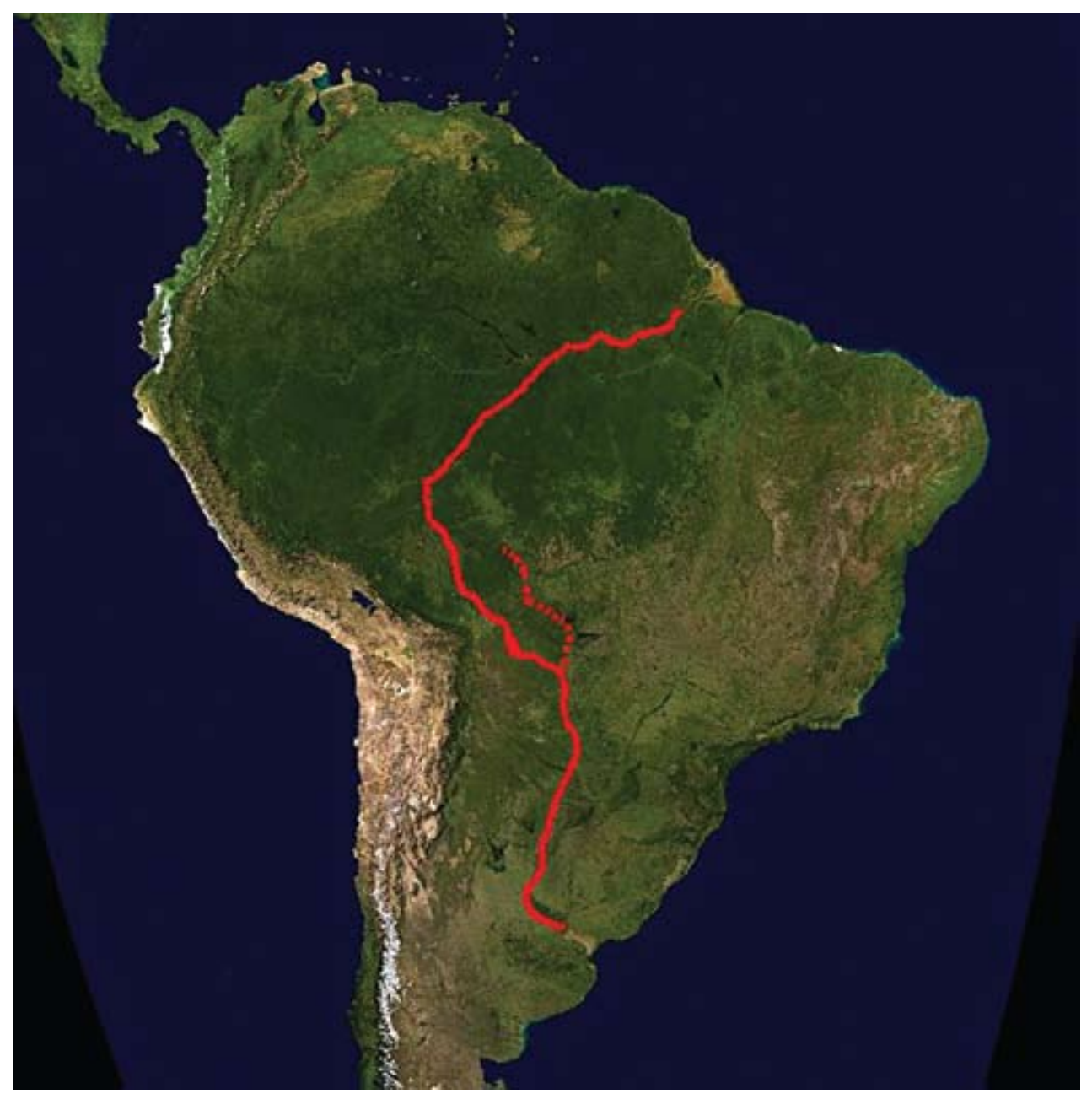

Figura 1 - Mosaico Modis utilizado neste trabalho, reproduzindo a América do Sul segundo cores naturais

situações geomórficas mais discretas, como aquelas dos divisores de variões, banhados e pantanais, bem como os interflúvios planos e altos (platôs), que acomodam os divisores Guaporé-Paraguai e Amazonas-Paraná/Prata.

Os mosaicos SRTM foram submetidos aos mesmos processos de correção geométrica e de geoprocessamento anteriormente descritos para o Modis.

Os mosaicos de radar suportados por imagens Landsat-5, por mapas $1: 1.000 .000$ da FIBGE e por dados WFI-CBERS serviram como base principal de análise, reconhecimento e traçado do mito da llha-Brasil (Figura 4). Os estudos dirigidos aos enlaces (capturas de meandros) das duas grandes bacias hidrográfica, Amazonas e Paraná, foram feitos primeiramente sobre a carta ao milionésimo da FIBGE.

Os enlaces ou zonas de captura, foram posteriormente analisados sobre 


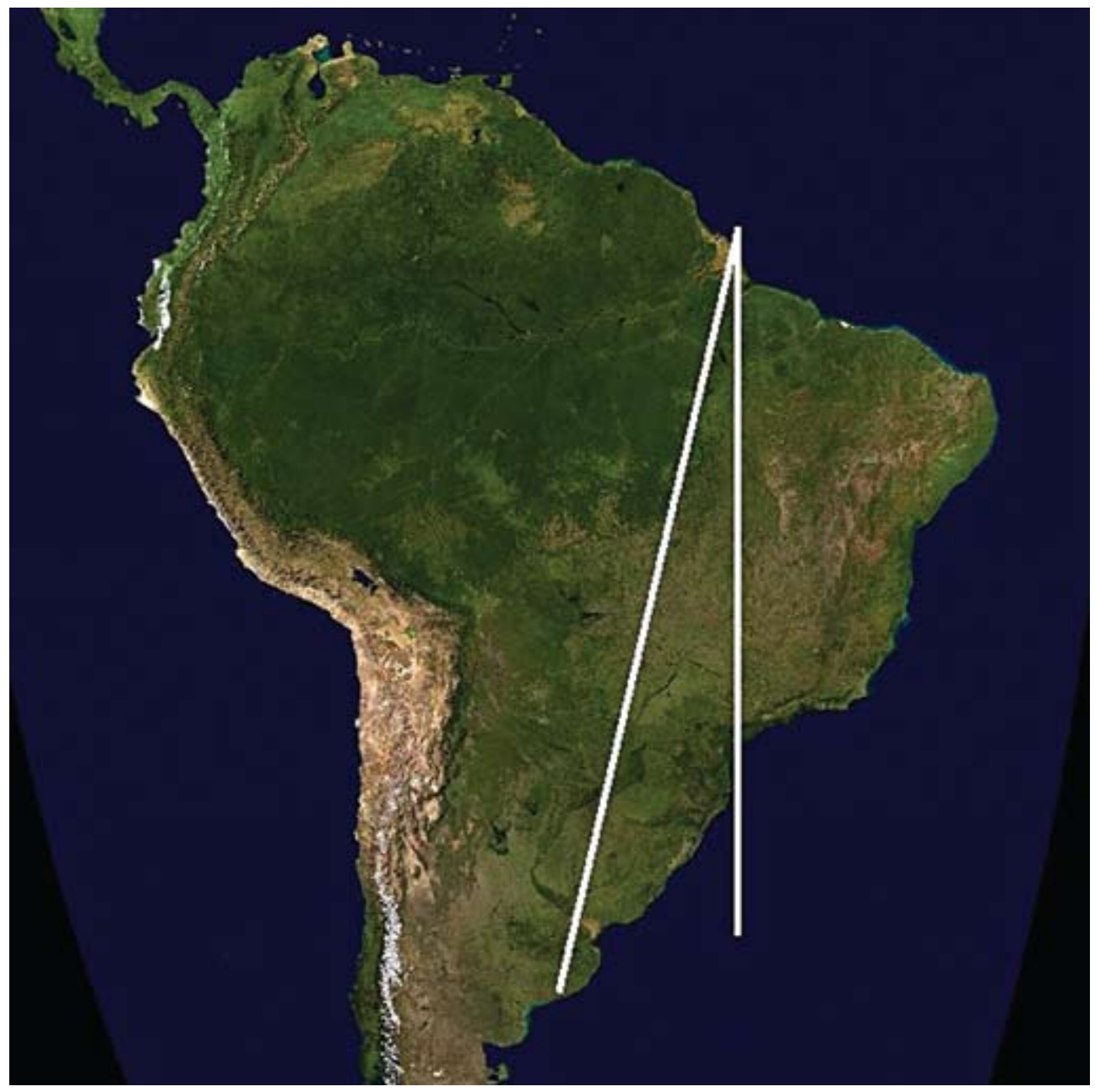

Figura 2 - Transposição da Linha de Tordesilhas no Mosaico Modis, com base na Carta Geral do Brasil do Roteiro dos sinaes..., de Luís Teixeira, século XVI.

imagens WFI-CBERS e Landsat-5, respectivamente nas escalas 1:1.000.000 e $1: 250.000$.

Uma vez definidos os cursos de água e os banhados que se interligam nas cheias correntes, ou nas da história recente (ver item Ilha Brasil), os limites foram transpostos para mosaicos SRTM. A figura 4 exemplifica o mosaico subamostrado com os limites da llha Brasil que foram apresentados pelos nativos aos descobridores em 1500. A figura 5 apresenta o enlace mais provável das duas grandes bacias sul-americanas, situado na borda oeste da Chapada dos Parecis (veja adiante o item Divisor Amazonas-Paraná/Prata).

A regionalização dos limites da llha Brasil e do enlace principal das duas bacias hidrográficas foi facilitada enormemente pela utilização do Mapa de Cobertura Landsat/CBERS escala $1: 10.000 .000$ em plano digital. 


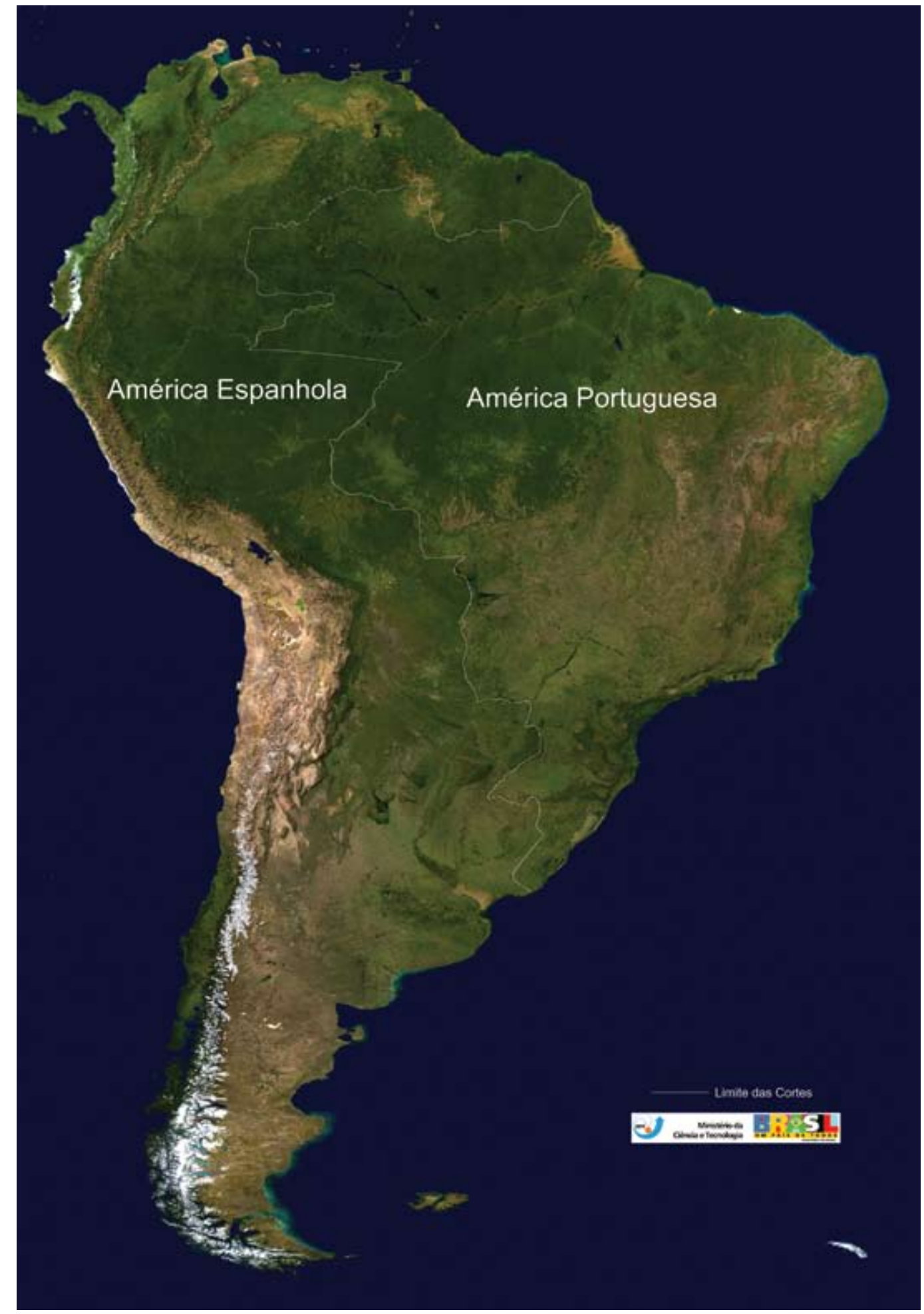

Figura 3 - Transposição do Mapa das Cortes. Mapa de Cobertura Landsat/CBERS, em plano digital, na escala $1: 10.000 .000$. 


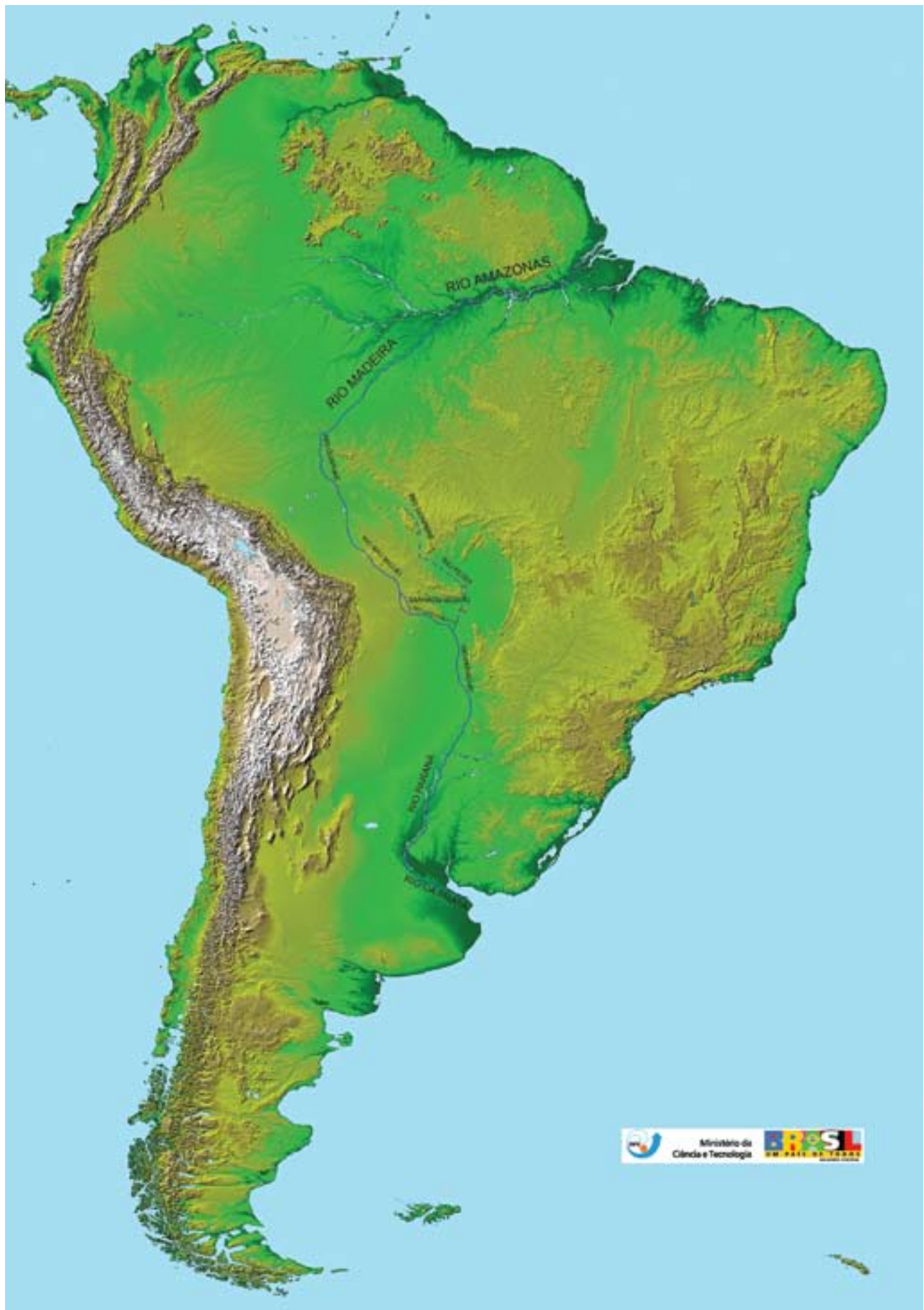

Figura 4 - Exemplo de mosaico subamostrado com a identificação da llha Brasil na cartografia quinhentista. A imagem apresenta o enlace mais provável das duas grandes bacias sul-americanas, na borda oeste da Chapada dos Parecis (ver o item Divisor Amazonas-Paraná/Prata). Mosaicos de radar suportados por imagens Landsat-5, por mapas 1:1.000.000 da FIBGE e por dados WFI-CBERS. 


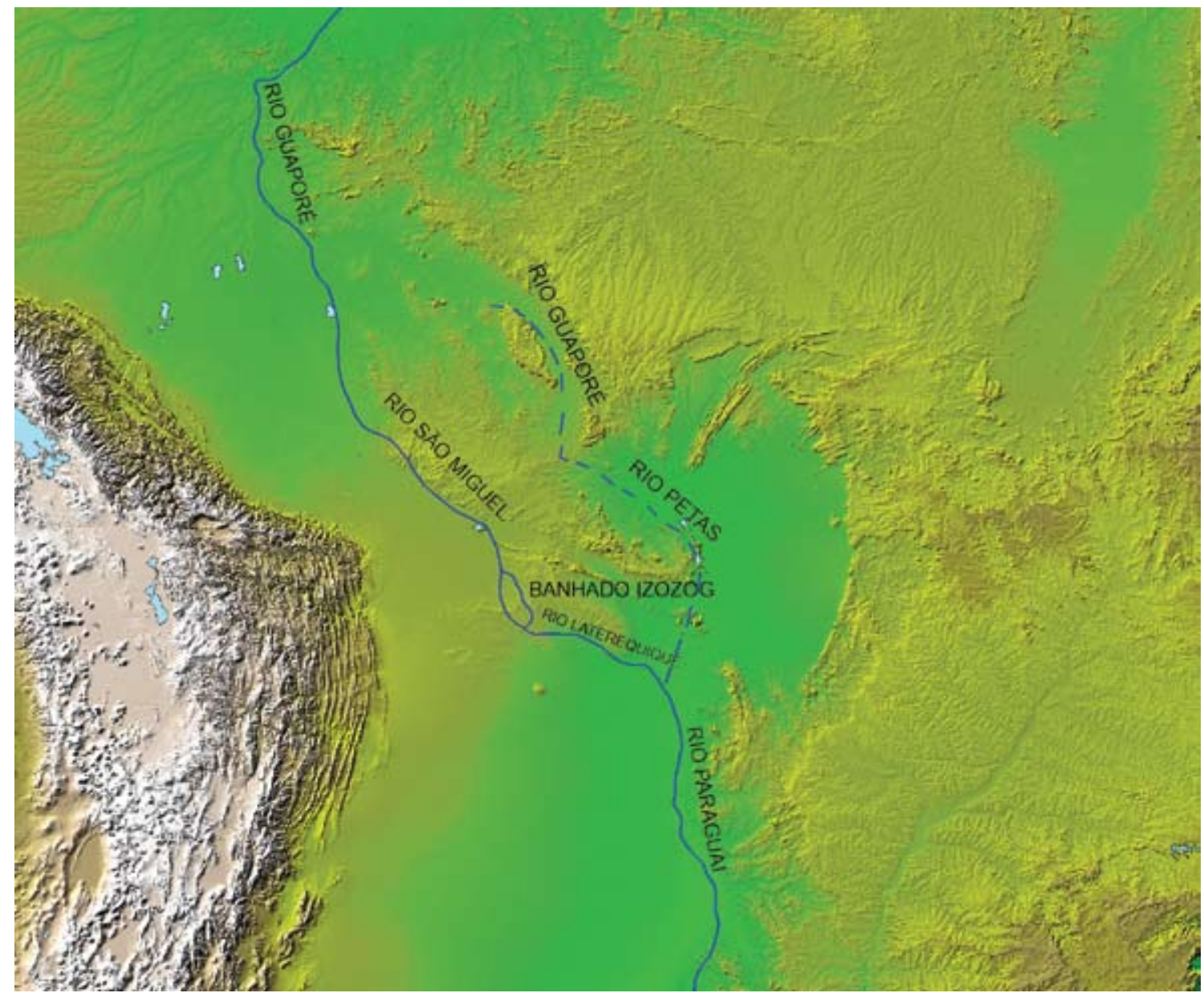

Figura 5 - Detalhe do sistema hídrico que faz a conexão entre as bacias do Prata e Amazônica.

\section{mito llha Brasil}

A leitura integrada do território sul-americano realçada em relevos pelo Radar Topográfico do Ônibus Espacial-SRTM permitiu entender mais facilmente o mito ou o conceito da llha Brasil. $\bigcirc$ mito foi concebido pelos nativos brasileiros pré-colombianos e mantido em memória coletiva verbal e eventualmente gráfica, mas não cartográfica. $\bigcirc$ mosaico SRTM permitiu que se visualizasse de uma forma mais concreta a llha Brasil, seguindo o conjunto de terras baixas ocidentais - que deixa o vale do Amazonas pelo rio Madeira para buscar os variões do Guaporé e os banhados do Paraguai até chegar ao rio Paraná - e daí prosseguir para o Atlântico Sul.

Esta região compreende a passagem da nascente do rio São Miguel, afluente do Guaporé, seguindo para sul através da laguna Concepción, passando 
os banhados del lzozog, todos eles sítios localizados em território boliviano. Desses banhados, o limite chega ao rio Lateriquique, marcador local da fronteira.

O conceito da llha Brasil apresentado pela imagem SRTM é bem diferente daquele que busca a captura ou a ligação de vertentes, perenes ou não, que interligariam localmente duas grandes bacias hidrográficas. A imagem demonstra que a ligação poderia ser mais do que uma vertente ou um riacho capturado, e, sim, um domínio extenso e largo, mas não profundo, por onde se poderia navegar com eficiência com remos e velas. Os variões e banhados poderiam ser muito mais amplos em épocas pré-colombianas, principalmente as anteriores ao século XV. A pequena era glacial, instalada a partir de 1400 A. D., certamente ajudou a desmanchar a llha Brasil na medida em que, em 100 anos (1500 A. D.), as geleiras aumentaram, os mares regrediram e muitos variões e banhados secaram. Quando os descobridores chegaram, o mito existia, mas não o fato. A imagem SRTM mostra que, geomorficamente, a llha Brasil existiu e poderá retornar pelo aumento das temperaturas globais, crescimento do nível do mar e derretimento das geleiras. Dados mostram que a pequena idade de gelo encerrou-se ao redor de 1850 A. D., ingressando-se, então, em um novo período de aquecimento. Tal mudança segue modelos matemáticos de câmbios climáticos globais, suportados por dados paleoclimáticos extraídos de sondagens de gelos antárticos ${ }^{2}$ e de anéis de crescimentos de árvores centenárias ${ }^{3}$. $\bigcirc$ mosaico da Figura 4 mostra o desenho mais provável do contorno da llha Brasil, seguindo na Bolívia os grandes banhados (traço esquerdo). Nessa mesma figura, o traço próximo à direita indica o mais provável enlace perene das bacias Amazonas-Paraná/Prata.

\section{Divisor Amazonas-Paraná/Prata}

A busca do enlace mais perene entre as duas bacias através de uma vertente local foi feita seguindo a mesma metodologia aplicada ao estudo da llha Brasil. Basicamente quatro regiões foram estudadas: i) Vale do rio Jauru; ii) Chapada dos Parecis; iii) Alto rio Araguaia, iv) Alto rio Guaporé. As regiões se encontram todas no estado do Mato Grosso.

1) Vale do rio Jauru.

Seu afluente, rio Iguapeí, encontra a vertente formadora do rio Alegre à montante de Porto Espiridião. O rio Alegre flui para o rio Guaporé. O rio lguapeí drena para o rio Paraguai. As coordenadas deste enlace são: S16:00 e W59:30;

II) Chapada dos Parecis.

$\bigcirc$ divisor da Chapada é cortado pelo rio Jauru. Este rio encontra a cabeceira do Córrego [lico-ré] que drena para o rio Sacre, formador do Papagaio que pertence ao alto vale do rio Juruena. $\bigcirc$ local é denominado Sítio Fonte de Pau. Suas coordenadas são: S14:30 e W58:35; 
Sítio localizado próximo à cidade de Taquari. Ali o córrego homônimo está capturando o ribeirão Guariroba. O Taquari drena para o Pantanal, o Guariroba drena para o Araguaia. Coordenadas: S17:48; W53:02.

IV) Alto rio Guaporé.

No alagado chamado Melgueira, em território boliviano, nascem os rios La Fortuna e Barbado. O primeiro corre para o rio Paraguai e o segundo é uma das nascentes do rio Guaporé. O alagado conforma uma situação típica de águas perenes e emendadas. As coordenadas são: S1 6:1 5 e W59:40. Localmente a área é chamada nos mapas como Sítio Belizário.

Os três primeiros sítios conformam vertentes enlaçadas sazonalmente pelas cheias ou sujeitas a captura, em um futuro próximo, fruto da erosão remontante. O quarto sítio descrito conforma uma nascente perene fluindo para as duas grandes bacias. Este local foi selecionado como a área de conexão corrente entre as águas amazônicas e platinas. Na figura 5 este limite aparece como linha intermitente à direita em contraponto ao traçado à esquerda que indica o limite da llha Brasil.

Bandeiras, monções e tropeirismos

Os caminhos para o interior seguidos pelos pioneiros paulistas, tanto em rios (monções) quanto no terreno (bandeiras e tropeirismos), foram recuperados a partir de devotado trabalho de pesquisa de Iris Kantor e Beatriz Bueno (Figura 6). Outro trabalho consistiu no reconhecimento de vilas, aldeias e corruptelas das épocas passadas, ao longo das quais os caminhos foram estabelecidos, nas cidades e distritos com nomes inscritos na Cartografia atual. Com base neste trabalho foram transpostos os marcos zeros dos sítios urbanos correntes, definidos pela FIBGE, para os mosaicos Modis (Figuras 7 a 12). A união entre os pontos relativos aos marcos zeros delineou o alinhamento das trilhas em terreno. As trilhas foram posteriormente transferidas para os mosaicos Modis sendo apresentadas no banco de uma maneira individual e também em conjunto. $O$ conjunto destas trilhas demonstra que muitas rodovias atuais tiveram influência das trilhas antigas. Esta associação já havia sido observada quando da recuperação da trilha do Anhanguera entre São Paulo e Goiás, em trabalho anterior ${ }^{4}$. As figuras 7 a 12 também representam os diversos limites que as capitanias paulistas mostraram desde suas definições originais. 


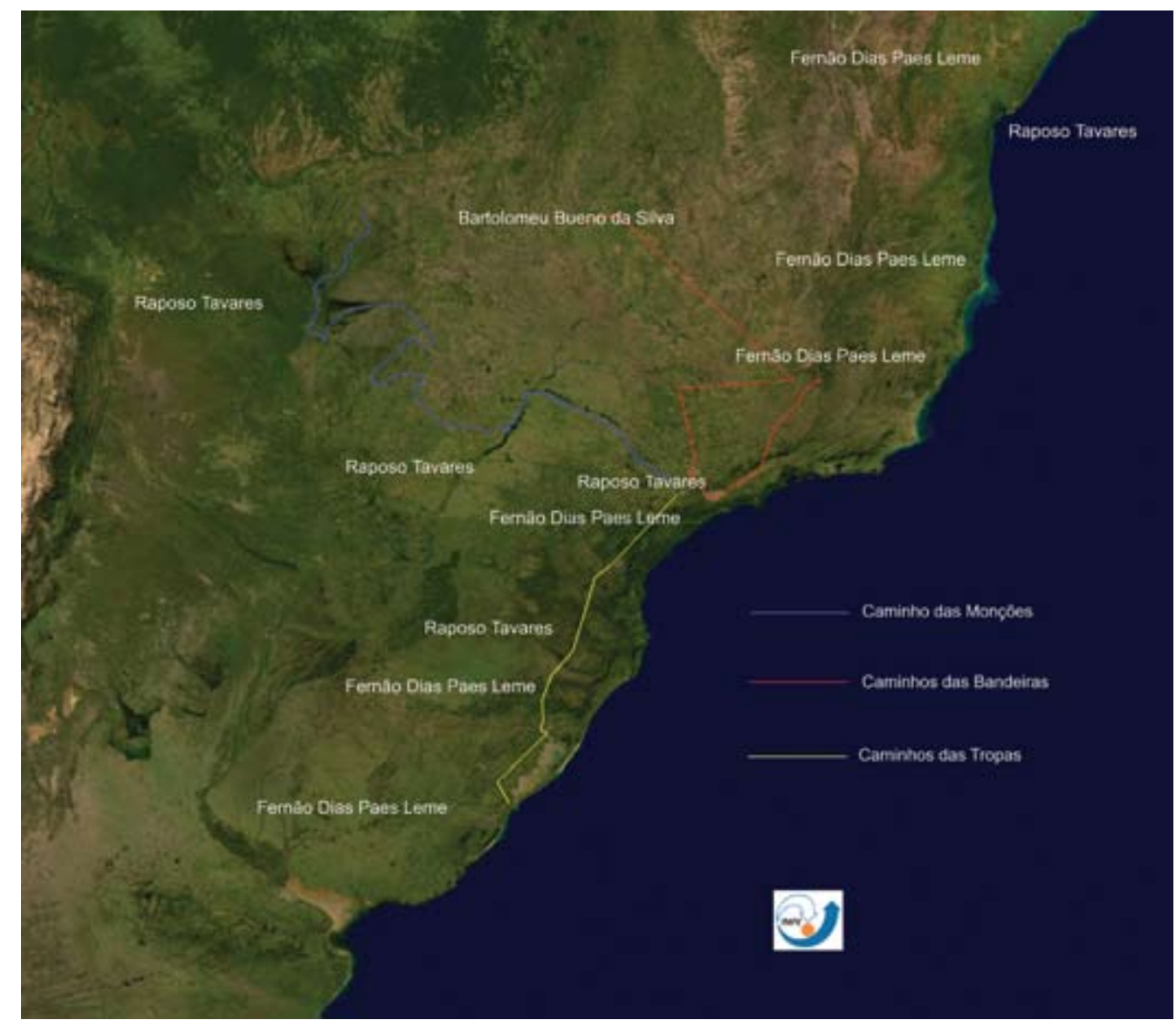

Figura 6 - Exercício de transposição das rotas das bandeiras, das monções e dos tropeiros conforme o célebre Mapa das Bandeiras elaborado por Affonso Taunay, em 1921.

Conclusões

5. FOWLES, 2000

6. Reeves, 1974; El Baz, 1997; NASA-JPL, 2000

$\bigcirc$ uso de sensores remotos para sustentar estudos históricos é pouco conhecido ${ }^{5}$, ao contrário do que ocorre em estudos arqueológicos, que fazem profícua utilização tanto de instrumentos óticos quanto de microondas ${ }^{6}$. Neste sentido, este trabalho tem um lado pioneiro e inédito. Existe, portanto, muito a ser aprendido.

Os resultados até aqui alcançados mostram que estes novos métodos têm muito a contribuir para as ciências históricas, assim como tem sido em arqueologia.

Tal integração entre cientistas da área de humanas com aqueles da área tecnológica se mostrou altamente produtiva para ambos, tanto em termos de novas idéias como de novos procedimentos, evidenciando o relevo da cooperação entre a Cátedra Jaime Cortesão e o Instituto Nacional de Pesquisas Espaciais (INPE). 


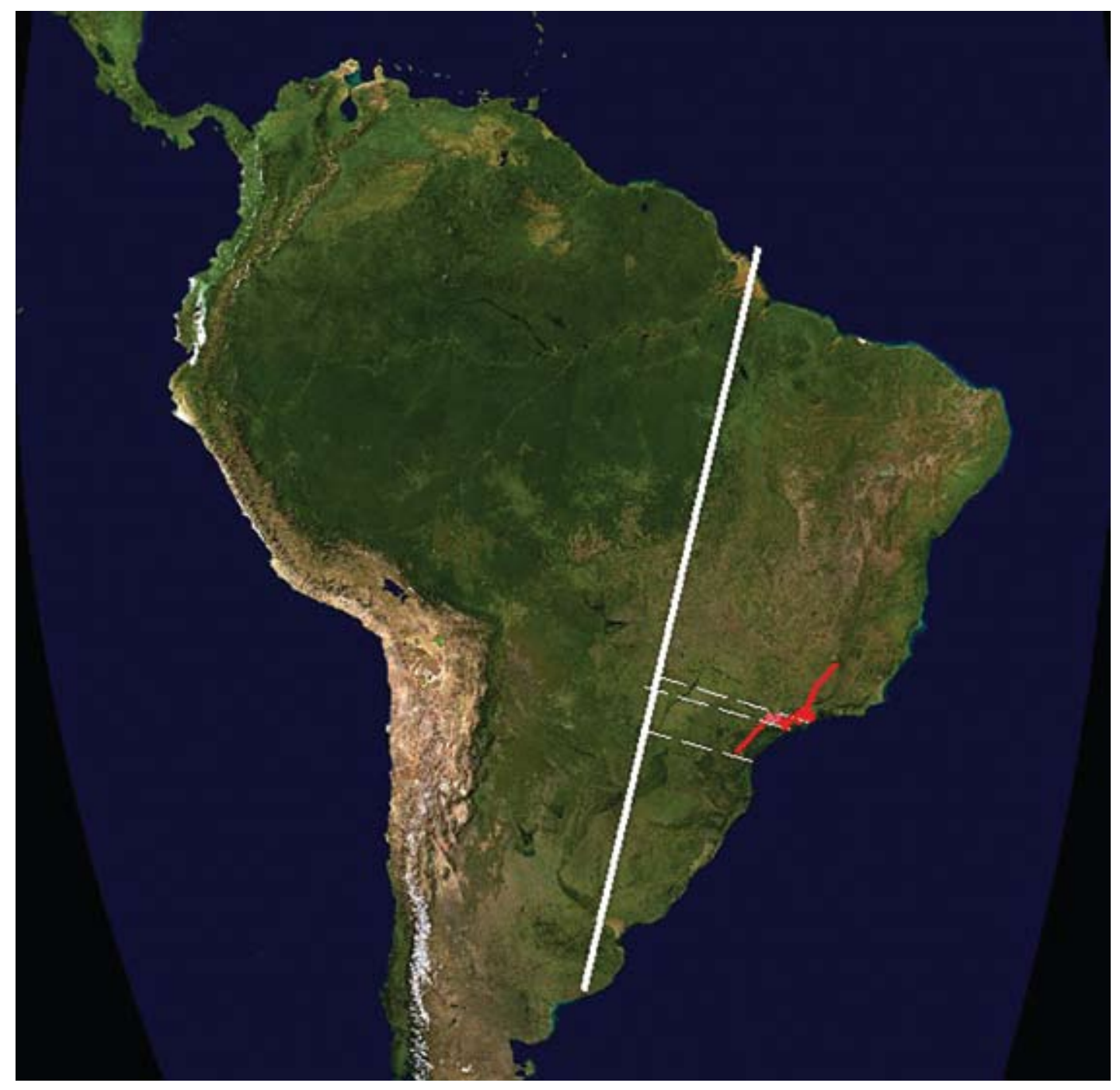

Figura 7 - Detalhe do exercício de transposição dos limites das capitanias de São Vicente e de Santo Amaro (1534-1711) conforme Luís Teixeira Albernaz em cerca de 1589; e, esboço das rotas terrestres segundo descrições dos sertanistas. 


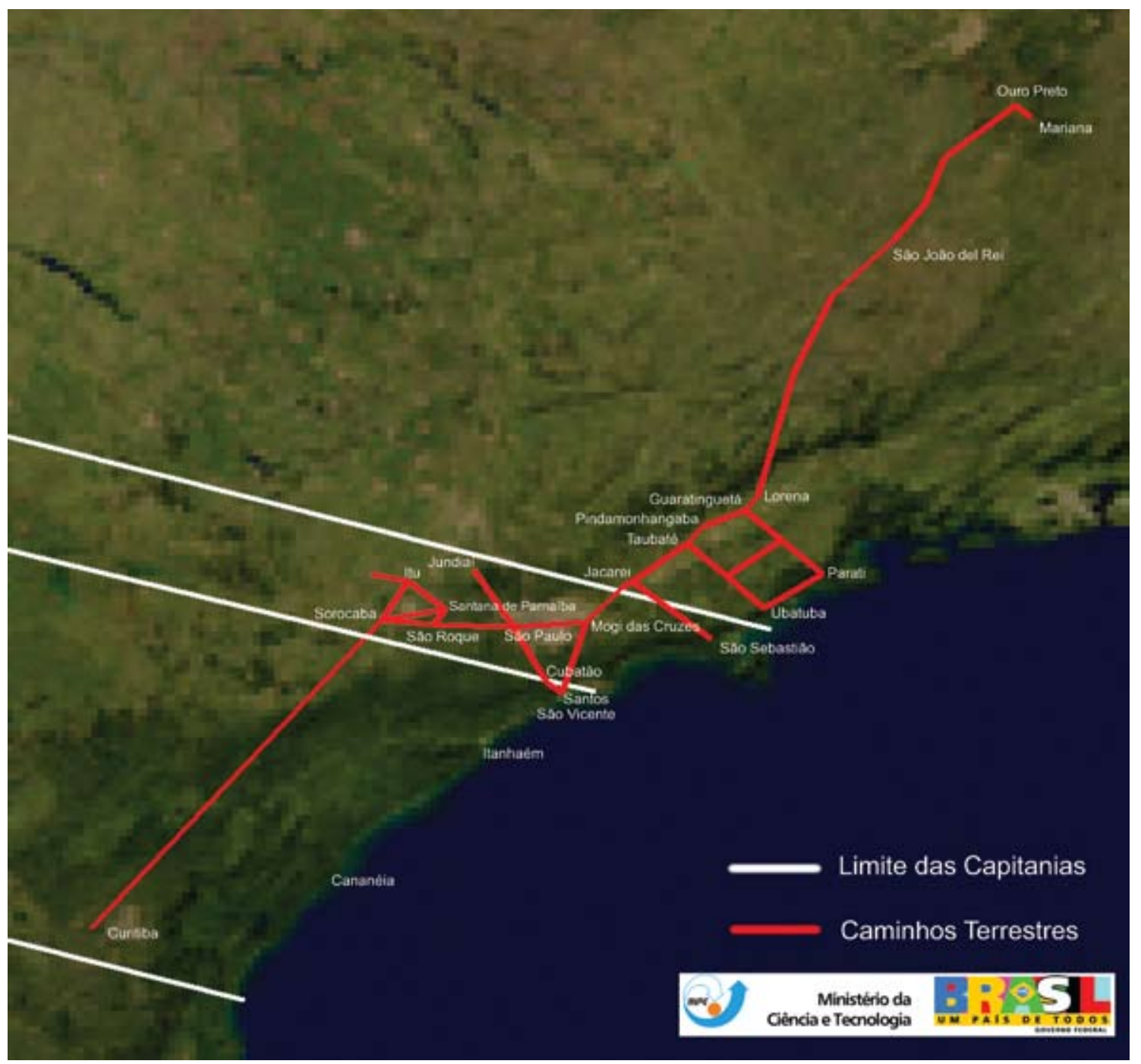

Figura 8 - Detalhe do exercício de transposição dos limites das capitanias de São Vicente e de Santo Amaro (1534-171 1) conforme Luís Teixeira Albernaz em cerca de 1589; e, esboço das rotas terrestres segundo descrições dos sertanistas. 


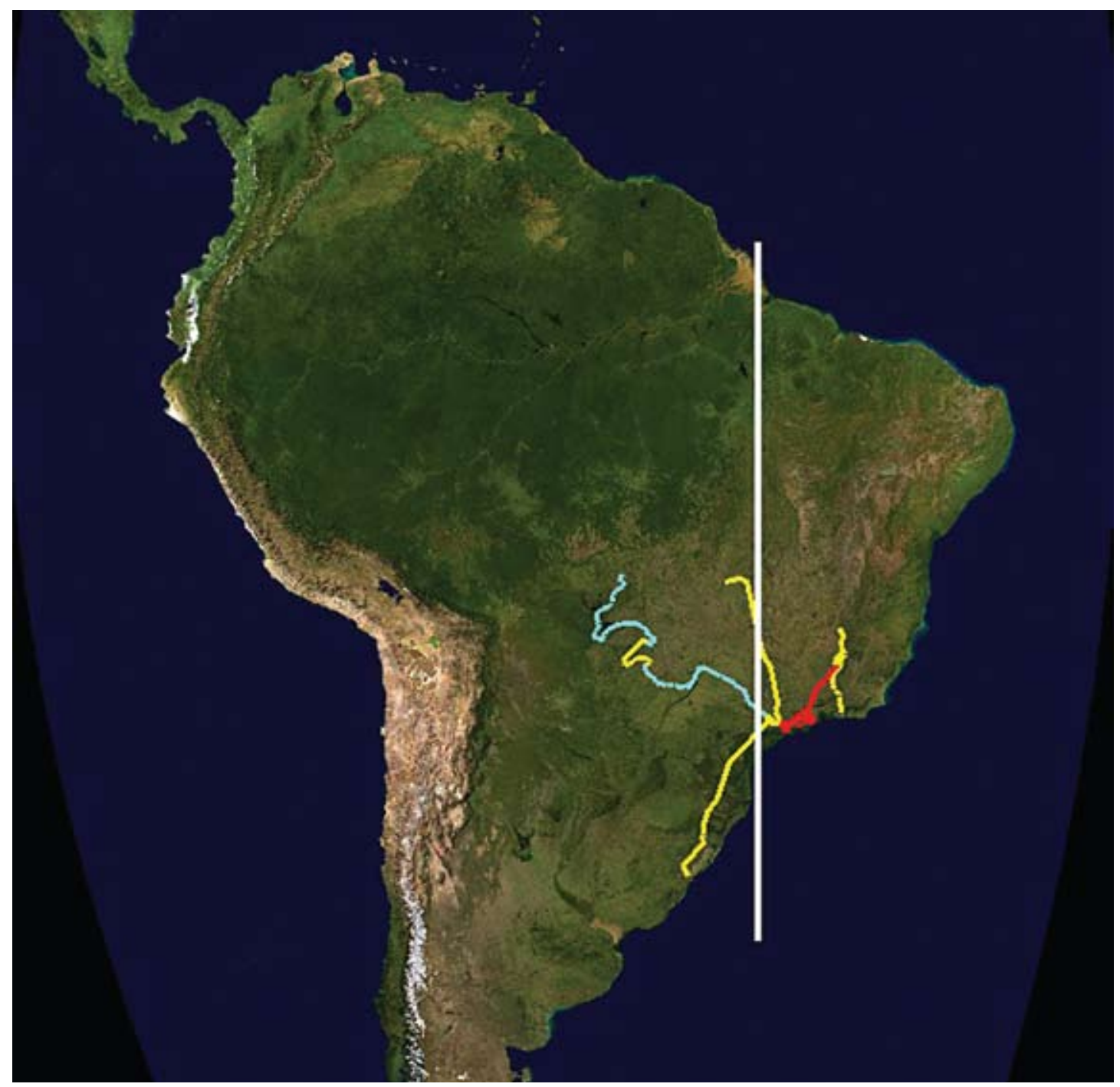

Figura 9 - Detalhe do exercício de transposição dos limites da Capitania de São Paulo (171 1-1765) e identificação da rede de caminhos, vilas e cidades segundo os mapas da época. 


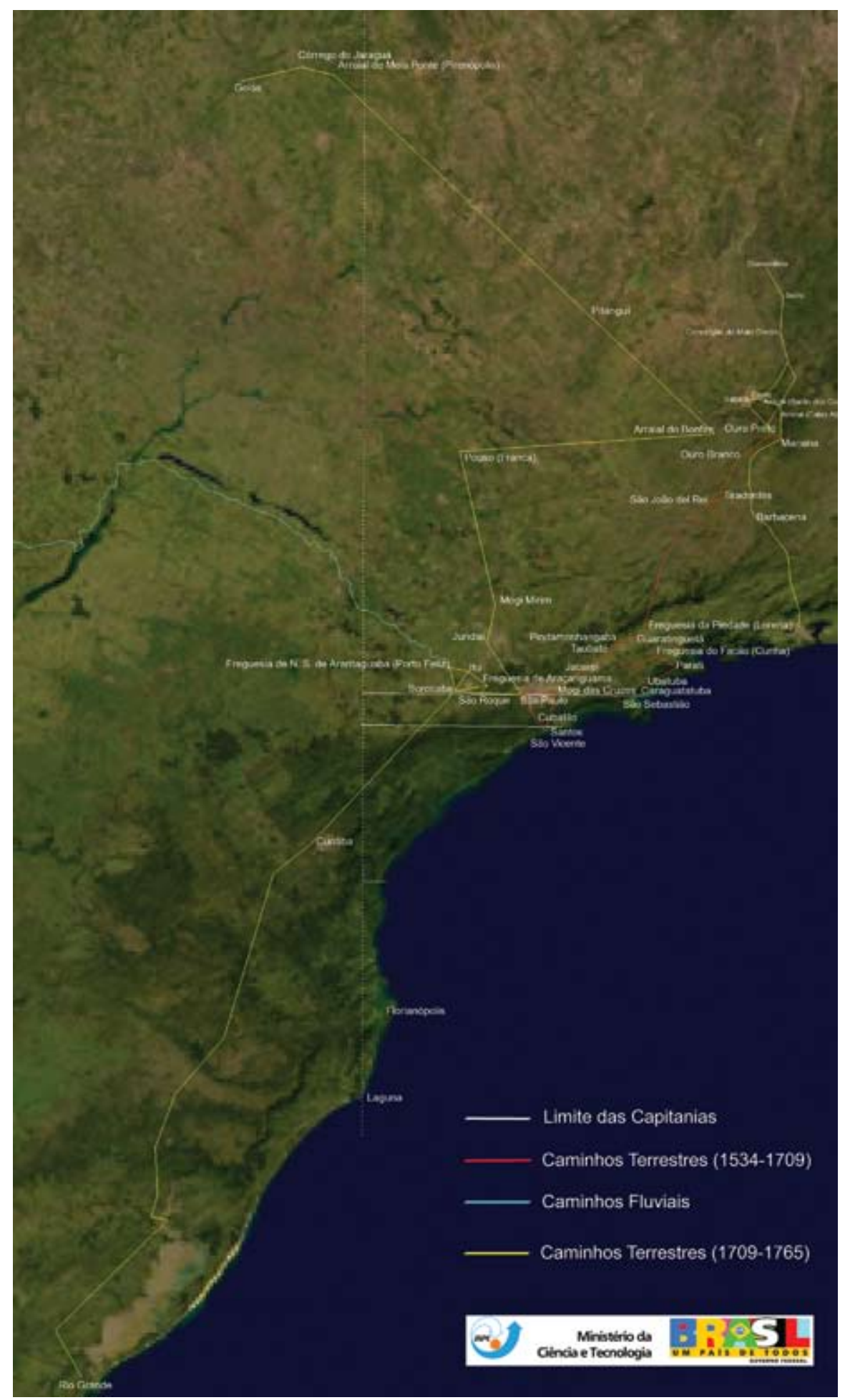

Figura 10 - Detalhe do exercício de transposição dos limites da Capitania de São Paulo (171 1-1765) e identificação da rede de caminhos, vilas e cidades segundo os mapas da época. 


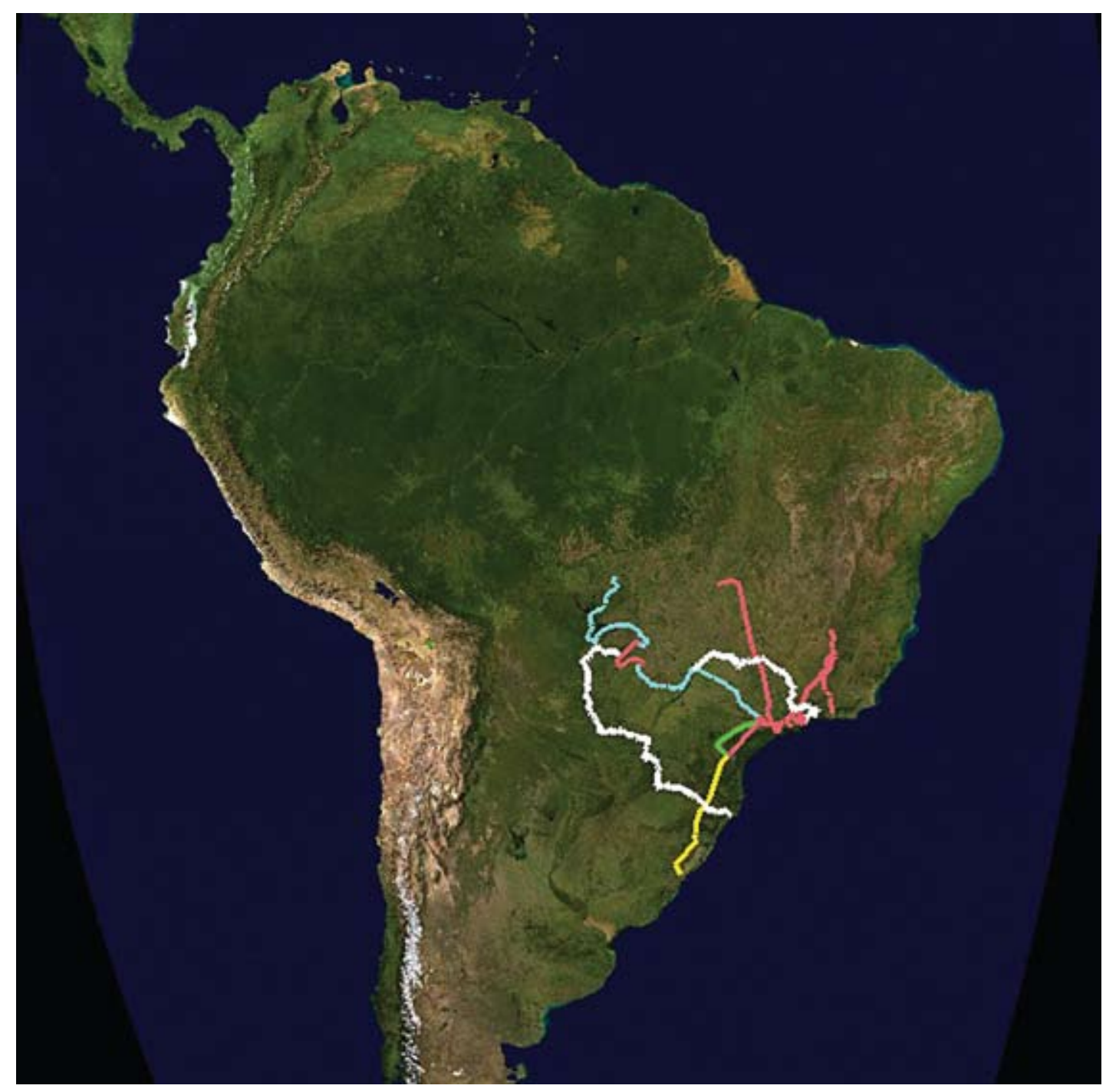

Figura 11 - Detalhe do exercício de transposição dos limites da Capitania de São Paulo (1765-1822) e identificação da rede fluvial e urbana segundo os mapas da época. 


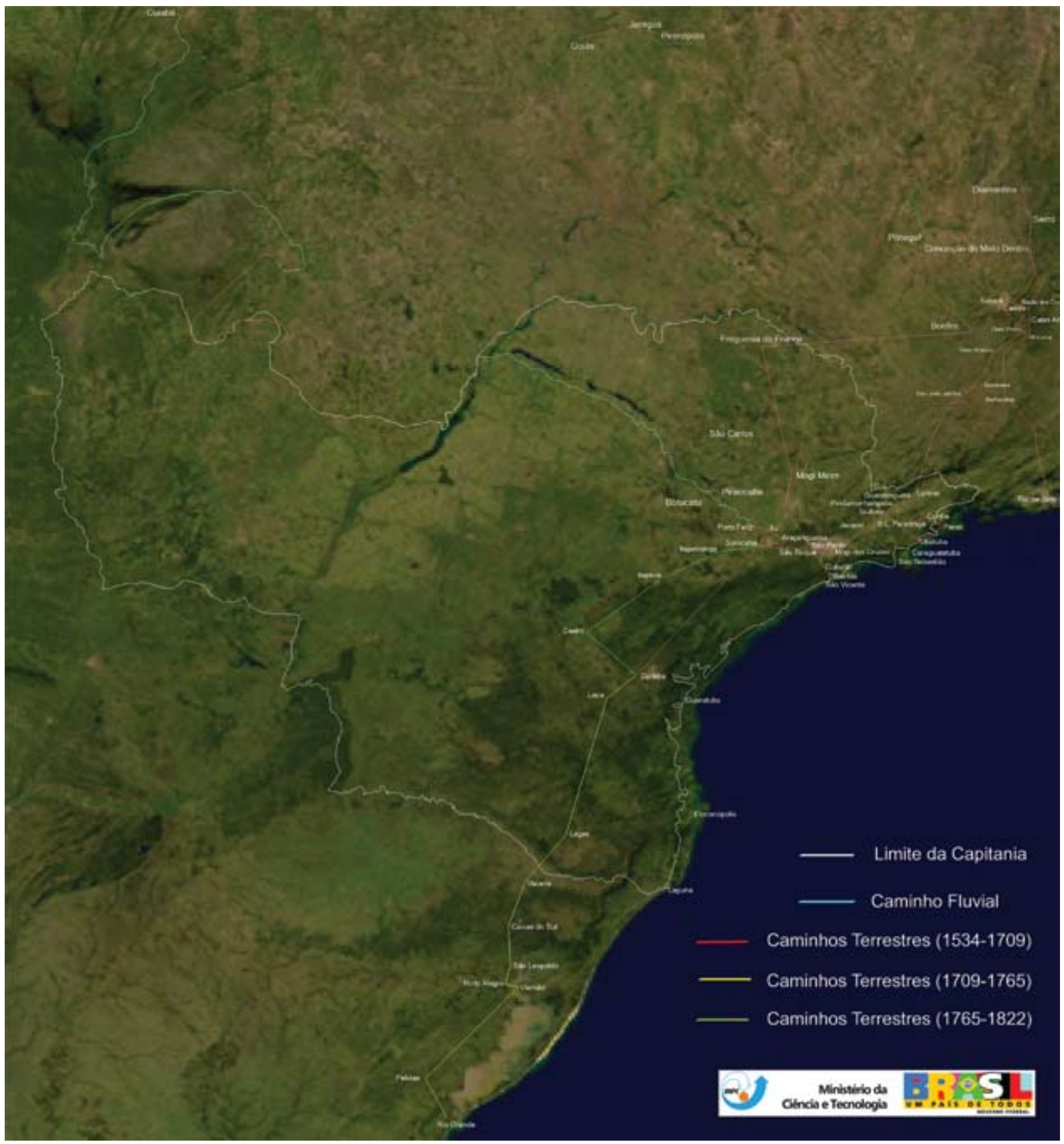

Figura 12 - Detalhe do exercício de transposição dos limites da Capitania de São Paulo (1765-1822) e identificação da rede fluvial e urbana segundo os mapas da época. 


\section{REFERÊNCIAS}

ELBAZ, F. Space age archaeology. Scientific American, New York, 277 (part 2), p. 40-45, 1997.

FOWLES, M.J.E. In the search of History. Imaging Notes Magazine. Denver, vol.15, n.6, nov-dez, p.18-21, 2000 .

MARTINI, P.R.; VIEIRA, R.M.S.P.; VALLES, G.F.; LEITE, F.A.; ARDUINO, R.G.C.; PIZANO, M. Sensoriamento remoto da Trilha do Anhanguera: mapeando o percurso de um pioneiro no Brasil do século XVIII. Anais do XI Simpósio Brasileiro de Sensoriamento Remoto. Belo Horizonte, 2003. CD ROM.

NASA-JPL. Seeing earth in a new way: SIR-C/X-SAR Experiment. Jet Propulsion Laboratory, California Institute of Technology, Pasadena-CA. Report JPL-400-823, 2000.

NORDEMANN, D.J.R; RIGOZO, N.R. As árvores contam uma história do Sol. Scientific American-Brasil. São Paulo, ano II, n. 14, julho, p. 30-37, 2003.

REEVES, R.G. (ed.). Manual of remote sensing. Falls Church, WI: American Society of Photogrammetry, 1974.

SIMÕES, J.C. O gelo também é nosso. Revista Pesquisa FAPESP, São Paulo, n.109, março, 2005. Entrevista para Marcos Pivetta.

Artigo apresentado em 8/2008. Aprovado em 12/2008. 